\title{
Desarrollo social: San Mateo de Otao y Callahuanca, 2017
}

Recibido: 17.12 .2018

Aprobado: 25.03.2019

\author{
Alida Isidora Díaz Encinas \\ Universidad Nacional Mayor de San Marcos \\ adiaze@unmsm.edu.pe \\ Carlos Meza Arquíñigo \\ Universidad Nacional Mayor de San Marcos \\ cmezaa@unmsm.edu.pe \\ Eduardo Maximiliano Vásquez Monge \\ Universidad Nacional Mayor de San Marcos \\ evasquezm@unmsm.edu.pe \\ Richard David Berrospi Rosales \\ Universidad Nacional Mayor de San Marcos \\ rberrospir@unmsm.edu.pe
}

\begin{abstract}
RESUMEN
Al analizar la evolución del desarrollo y los cambios sociales en la población de los distritos de San Mateo de Otao y Callahuanca, Huarochirí 2017, encontramos una serie de transformaciones, principalmente en la agricultura, originalmente de sustento, a una agricultura orientada a la comercialización, para el mercado interno y externo. Esto a pesar de la escasez de agua para el riego, el abandono de los pueblos y anexos que están por encima de 3,000 msnm y la migración de la población joven, restando fuerza a la mano de obra local. También verificamos la falta de atención al patrimonio cultural y a la educación, en cuanto a la salud prevalece la atención primaria. Finalmente para incentivar el proceso del desarrollo y cambios en los componentes sociales de San Mateo de Otao y Callahuanca se necesita implementar políticas de equidad espacial y acciones socioeconómicas para todos los pueblos y anexos, con una adecuada gestión del gobierno local en el uso de suelos y agricultura.
\end{abstract}

Palabras clave: desarrollo, cambios sociales, ruralidad, migración.

\section{Social development: San Mateo de Otao and Callahuanca, 2017}

When analyzing the evolution of development and social changes in the population of the districts of San Mateo de Otao and Callahuanca - Huarochirí 2017, we find a series of transformations, mainly in agriculture, originally from sustenance, to agriculture oriented towards marketing, for the internal and external market. This despite the shortage of water for irrigation, the abandonment of villages and annexes that are above 3,000 meters above sea level and the migration of the young population, detracting from the local workforce. We also verify the lack of attention to cultural heritage and education, in terms of health, primary care prevails. Finally, to encourage the process of development and changes in the social components of San Mateo de Otao and Callahuanca, it is necessary to implement spatial equity policies and socio-economic actions for all peoples and annexes, with adequate local government management in the use of land and farming.

KEYworDs: development, social changes, rurality, migration. 


\section{Introducción}

A I analizar la realidad de los distritos Callahuanca y San Mateo de Otao descubrimos situaciones que traban el desarrollo integral de los distritos: el abandono de las zonas de más de $3500 \mathrm{msnm}$, despoblamiento por efectos de migración a zonas intermedias donde se encuentran las nuevas capitales de estos distritos y la migración de los jóvenes en busca de mejores oportunidades. Observamos el desaprovechamiento del recurso agua por carencia de represas para almacenar el agua en época lluviosa la cual discurre al mar desperdiciándose. Por otro lado, las estadísticas muestran altas tasas de desnutrición crónica en ambos distrito; pero a partir de 2009 al 2017 se observa un descenso, lo que repercutirá a futuro en la formación intelectual de calidad y en la mano de obra calificada para fomentar el desarrollo sostenible integral. Los distritos tienen recursos naturales para el turismo ecológico y zonas arqueológicas que deben ser puestas en valor para promover el patrimonio cultural. Se observa descuido en el manejo y dirección de los centros de salud y de la educación. Los sembríos de pan llevar han ido cambiando a través del tiempo para dar preferencia a los cultivos para el mercado como chirimoya y palta, apreciados en los mercados nacionales e internacionales.

\section{Antecedentes}

El Banco Mundial manifiesta que: «El desarrollo social se centra en la necesidad de 'poner en primer lugar a las personas' en los procesos de desarrollo. La pobreza no es solo un tema sobre los ingresos bajos; se trata también de la vulnerabilidad, la exclusión, las instituciones poco transparentes, la falta de poder y la exposición a la violencia. El desarrollo social promueve la inclusión social de los pobres y vulnerables empoderando a las personas, creando sociedades cohesivas y resilientes, y mejorando la accesibilidad y la rendición de cuentas de las instituciones frente a los ciudadanos. Al asociar los Gobiernos, las comunidades, la sociedad civil, el sector privado y los marginados, incluidos los pueblos indígenas y las personas con discapacidad, el desarrollo social transforma la compleja relación entre las sociedades y los Estados en intervenciones concretas.» ${ }^{1}$

Asimismo, la CEPAL, en el documento Desarrollo social inclusivo, Una nueva generación de politicas para superar la pobreza y reducir la desigualdad en América Latina y el Caribe, encuentra que «los elementos centrales de lo que se denomina 'desarrollo social' han permanecido constantes en el tiempo. En ello el objetivo fundamental de lograr los mayores niveles posibles de bienestar para todas las personas en un marco de libertad. En los documentos intergubernamentales posteriores, hay acuerdo en este objetivo. También existe un consenso general en el sentido de que el desarrollo social abarca una amplia variedad de áreas que deben ser abordadas por distintas organizaciones internacionales, incluidas la educación, la salud, el empleo, el delito, la migración y el desarrollo humano en general» (CEPAL 2015: 14).

Bravo, Olga realizó un estudio sobre desarrollo local como estrategia socio-política de cambio en Ecuador, plantea que los ámbitos jurídico y práctico del desarrollo local en Ecuador se aproxima a una estrategia socio-política de transformación social, la autora presenta un modelo constituido por tres ejes: «teórico, bajo el supuesto de la sociedad como un sistema complejo adaptativo; estratégico, construido como un modelo de desarrollo endógeno; y, operativo, mediante la utilización de herramientas de la planificación, en procesos participativos, reflexivos y críticos» (Bravo 2016: 98).

Asimismo, Melvin Bermúdez, en la investigación «Desarrollo local del cantón de Coto Brus, sin desarrollo regional. ¿Realidad o utopía?», considera que según la teoría de la CEPAL referente al desarrollo el centro había logrado un mayor nivel de desarrollo porque fue ahí donde penetraron primero las técnicas capitalistas de producción y se operaron los avances tecnológicos más importantes, muestran que a las periferias se les consideraba como suplidores de materia prima y en donde su grado de rezago económico y social estaba en relación directa con el rezago tecnológico y organizativo existente en estas economías. Basándose en esta teoría concluye "que no podría existir un desarrollo local del Cantón de Coto Brus,

1 Banco Mundial - Sitio web: https://www.bancomundial.org/es/topic/socialdevelopment/overview (Revisado: 14/12/2018). 
sin que exista un desarrollo de toda la región Brunca, pero para asegurar que el cantón pueda tener un desarrollo endógeno es necesario una relación comercial hacia afuera, lo cual es fundamental para disponer de una demanda agregada de bienes y servicios» (Bermúdez 2016: 95).

Vásquez y Medina (2010) en el artículo «La comunidad campesina de San Mateo de Otao", consideran que uno de los problemas más importantes de la comunidad es la escasez del agua, existen una siete mil hectáreas que no son cultivadas por este motivo y sugieren que sería necesario almacenar el agua en represas y evitar que siga discurriendo al mar, esto permitiría aprovechar la mano de obra de la comunidad para cultivar maíz, trigo, cebollas, etc. Otro problema son las enfermedades endémicas (Leishmaniasis) que afecta a los pobladores que están dedicados a la agricultura. Luego los autores concluyen que «la comunidad presenta un proceso de desintegración que empezó en fechas cercanas a la creación del distrito de San Mateo de Otao, proceso que se caracteriza por la individualización de los terrenos de propiedad comunal» (Vásquez y Medina 2010: 221).

\section{Ámbito geográfico}

Los distritos de Callahuanca y San Mateo de Otao pertenecen a la provincia de Huarochirí, están situados al Noreste de Lima, en la región de Lima Provincias, se localiza entre las Coordenada UTM: 322191 metros Este, 8698551 metros Norte y 342981 metros Este, 8698551 metros Norte; ocupan una área aproximada de: Callahuanca 50.84 $\mathrm{km}^{2}$, San Mateo de Otao $135.90 \mathrm{~km}^{2}$ con un total de $186.74 \mathrm{~km}^{2}$. Estos territorios se encuentran entre los $1200 \mathrm{msnm}$ y $4850 \mathrm{msnm}$ de altitud.

\section{Descripción paisajística}

De acuerdo a los niveles altitudinales, las ocho regiones naturales formuladas por el Dr. Javier Pulgar Vidal, el Modelo Digital construido para el proyecto

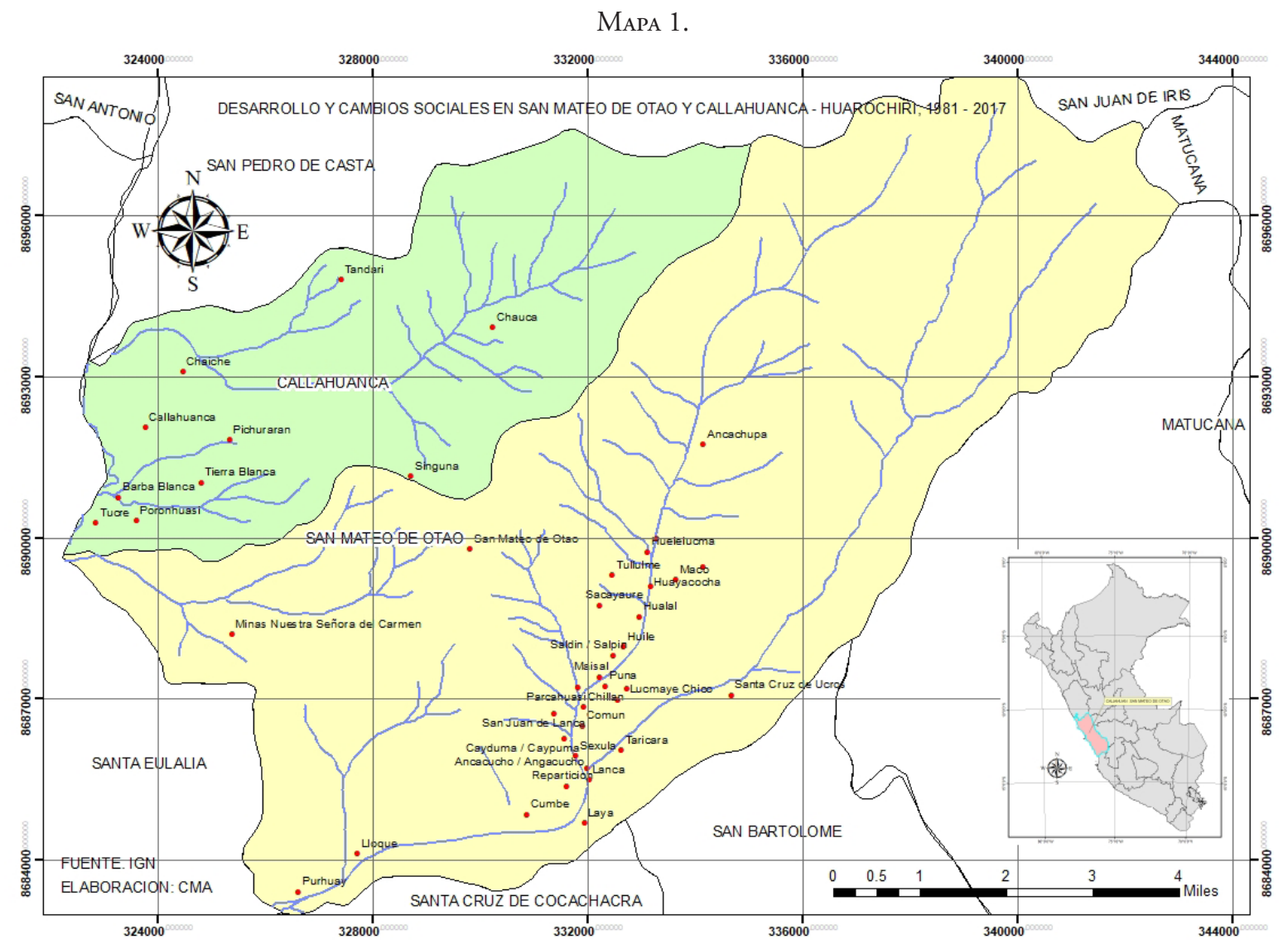

Fuente. IGN. Elaboración propia. 
y el trabajo de campo in situ; el paisaje varía entre los 1200 metros sobre el nivel medio del mar y 4850 metros sobre el nivel medio del mar con una extensión de $186.74 \mathrm{~km}^{2}$. Se identificaron las siguientes regiones altitudinales (ver mapa 2 ).

Yunga Marina, de 500 a $2300 \mathrm{msnm}$, valles estrechos de forma triangular cuyo vértice se introduce en los contrafuertes andinos occidentales, con clima cálido, el sol brilla casi todo el año y las lluvias se producen en los meses de diciembre a marzo, plantas como las xerofíticas y arbustivas resaltan: molle, lúcuma, chirimoya, palta, etc.; además la región está relacionada con la uta enfermedad endémica (Leishmaniasis) que está controlada.

Quechua, de 2300 a $3500 \mathrm{msnm}$, se caracteriza por presentar relieve de valles estrechos, como garganta, clima templado, con altas temperaturas en el día y en las noches con temperaturas bajas donde se localizan la mayor cantidad de los Pueblos como: Santa Cruz de Ucros, Canchacalla y otros anexos, por las características del clima y suelo se cultiva maíz, habas, palta, chirimoya y otros productos.

Suni o Jalca, de 3500 a $4000 \mathrm{msnm}$, caracterizada por altas elevaciones con cerros de fuertes pendientes, clima frio seco y disminución de la presión atmosférica que es el motivo del soroche o mal de altura; la cobertura vegetal son de plantas como el quinual, aliso, quishuar y las pasturas de ichu, paja, etc. En esta región se cultivan papas, quinua, cebada y es la zona de la ganadería lanar, de camélidos y caballar. En este espacio está situado el pueblo de San Mateo de Otao, antigua capital del distrito y se encuentran también algunos anexos.

Puna, de 4000 a 4800 msnm. Es la cabecera de cuenca de los distritos; presenta pequeñas altiplanicies y cerros con caída libre; con clima muy frio, con temperaturas promedio bajo cero en la sombra y temperatura promedio máxima de 8 grados centígrados a la sombra, que no es favorable para la vida normal del ser humano; se observan plantas con alto contenido

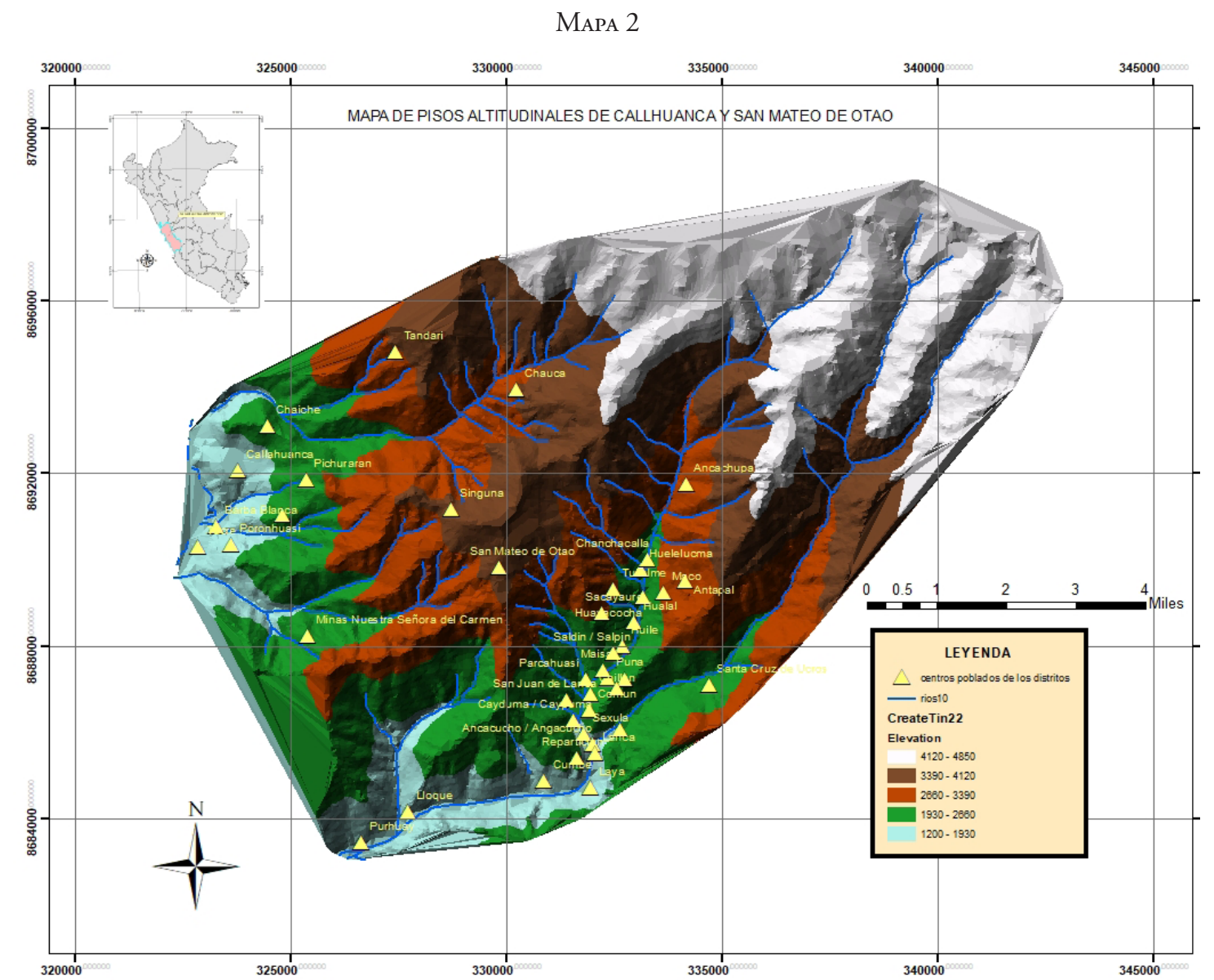

Fuente. IGN. Elaboración propia. 
MAPA 3

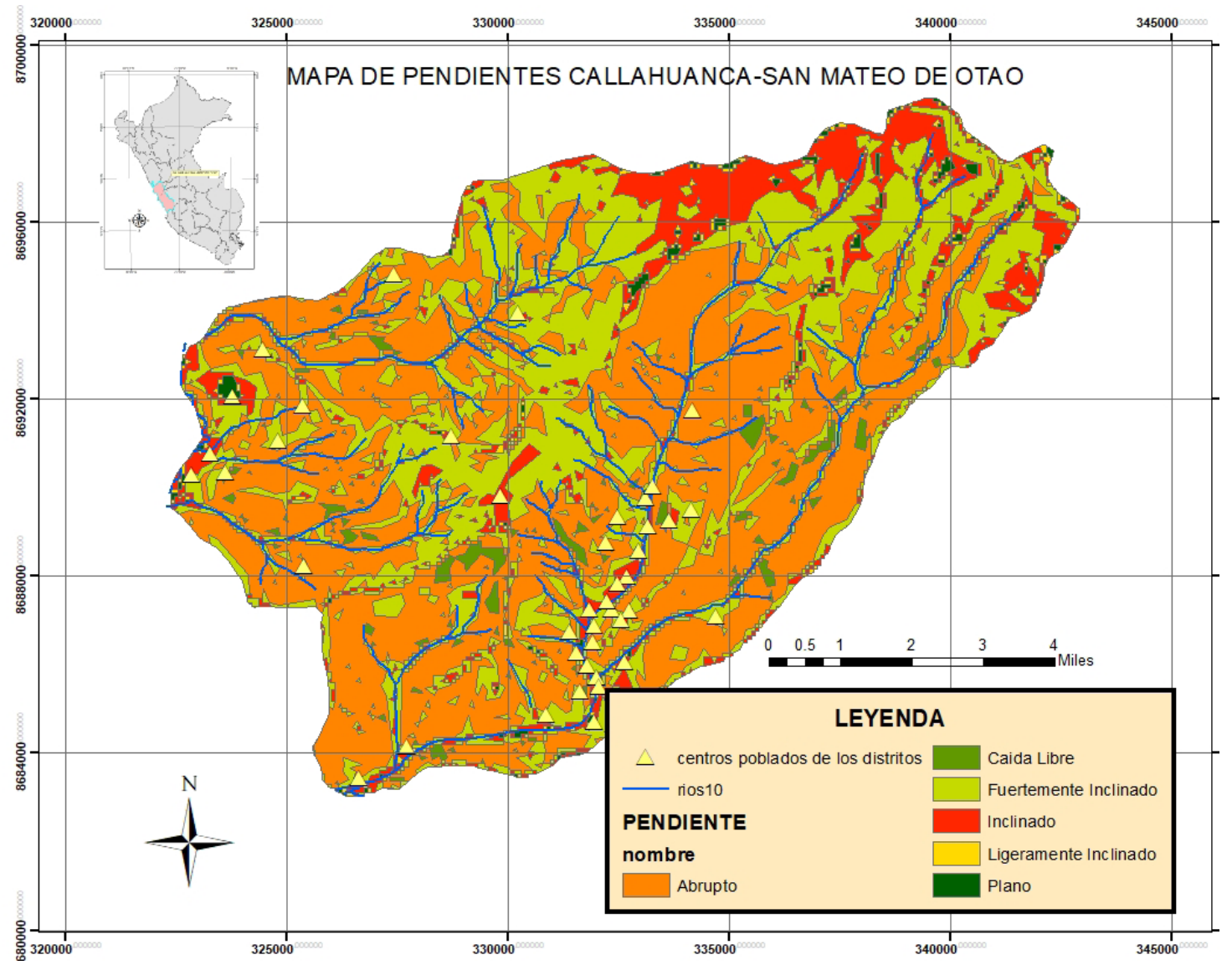

Fuente. IGN. Elaboración propia.

de aceite como la yareta, líquenes, musgos, etc. $\mathrm{Y}$ es apropiada solamente para crianza de camélidos.

Cordillera, más de $4800 \mathrm{msnm}$, observamos una pequeña zona climática nival, con características extremas de temperatura.

La configuración del relieve es muy accidentado lo que limita la agricultura intensiva; se aprovecha solamente las condiciones climáticas del fondo del valle, en este caso los arbustos de plantas como la Chirimoya, Palta, manzana, etc. que tienen gran demanda en los centros urbanos y para la exportación.

El estudio de las pendientes es muy importante para el análisis espacial. Según el mapa 3, se ha optado por la clasificación de pendientes por IGAC (Instituto Geográfico Agustín Codazzi) en 6 categorías: Plano, ligeramente inclinado, inclinado, fuertemente inclinado, caída libre y abrupto los cuales nos dieron como resultado: Las categorías de abrupto $(49.00 \%)$, caída libre $(2.00 \%)$ y fuer- temente inclinado (36\%) totalizando un $87 \%$, son tierras de conservación protección lo cual no tienen uso, salvo para el turismo de aventura u otra vocación que podría ser la minería de socavón y no de tajo abierto. Mientras que las pendientes: planas $(1.00 \%)$, ligeramente inclinado $(1.00 \%)$ e inclinado $(11.00 \%)$ con un total de $13 \%$, que se localizan en Callahuanca, Lanca, San Mateo de Otao y las punas de estos distritos.

\section{Descripción de las áreas productivas de Callahuanca y San Mateo de Otao}

El cuadro dos y mapa número 04, muestran que en los distritos de Callahuanca y San Mateo de Otao la agricultura bajo riego es de $6.15 \mathrm{~km}^{2}$ es decir el $3.32 \%$; espacio muy pequeño que deber ser ampliado; ganando terreno de las áreas de agricultura 
en andenería $41.29 \mathrm{~km}^{2}(22.11 \%)$ y agricultura en andenería para rehabilitación $1.10 \mathrm{~km}^{2}(0.60 \%)$; utilizando sistemas de regadío con técnicas modernas con la finalidad de incrementar la producción y productividad.

\section{Cuadro 1}

Desarrollo productivo de Callahuanca y San Mateo de Otao

\begin{tabular}{|l|l|r|r|}
\hline \multicolumn{1}{|c|}{ Descripción } & \multicolumn{1}{|c|}{$\begin{array}{c}\text { Área } \\
\mathrm{km}^{2}\end{array}$} & \multicolumn{1}{|c|}{$\begin{array}{c}\text { Área } \\
\%\end{array}$} \\
\hline 01 & Agricultura bajo riego & 6.15 & 3.32 \\
\hline 02 & Protección y conservación & 125.52 & 67.21 \\
\hline 03 & $\begin{array}{l}\text { Protección y conservación-Ganadería } \\
\text { intensiva }\end{array}$ & 11.81 & 6.31 \\
\hline 04 & $\begin{array}{l}\text { Protección y conservación-Ganadería } \\
\text { con limitaciones climáticas }\end{array}$ & 0.81 & 0.43 \\
\hline 05 & Agricultura en andenería & 41.29 & 22.11 \\
\hline 06 & $\begin{array}{l}\text { Agricultura en andenería para } \\
\text { rehabilitación }\end{array}$ & 1.10 & 0.60 \\
\hline 07 & Urbano & 0.04 & 0.02 \\
\hline & TOTAL & 186.74 & 100.00 \\
\hline
\end{tabular}

Fuente. Elaboración propia

\section{Referencias históricas}

\section{Distrito: San Mateo de Otao}

La Comunidad San Mateo de Otao fue reconocida como comunidad de indígenas por Resolución Suprema del 31 de octubre de 1942, disponiéndose su inscripción en el registro respectivo de la Dirección de Asuntos Indígenas del Ministerio de Salud Pública, Trabajo y Previsión Social. ${ }^{2}$ El 7 de noviembre de 1944 se promulgó la Ley N.o 10001 que crea el distrito de San Mateo de Otao. Posteriormente, mediante la Ley N. ${ }^{\circ} 13267$, del 5 de noviembre de 1959 , se dispone el traslado de la capital del distrito del pueblo de San Mateo de Otao al pueblo de San Juan de Lanca, donde se establecen las autoridades distritales y también las comunales. ${ }^{3}$ En la actualidad, el distrito es uno de los 32 distritos de la provincia de Huarochirí.

Dentro del distrito se encuentran las zonas arqueológicas de Marca Marca, Chaupimarca y Huarichaca que han sido declarados patrimonio

2 Oficio $\mathrm{N}^{\circ} 1240$, Dirección de Asuntos indígenas, Ministerio de justicia y Trabajo

3 El Peruano, 16.11 .1959

MAPA 4

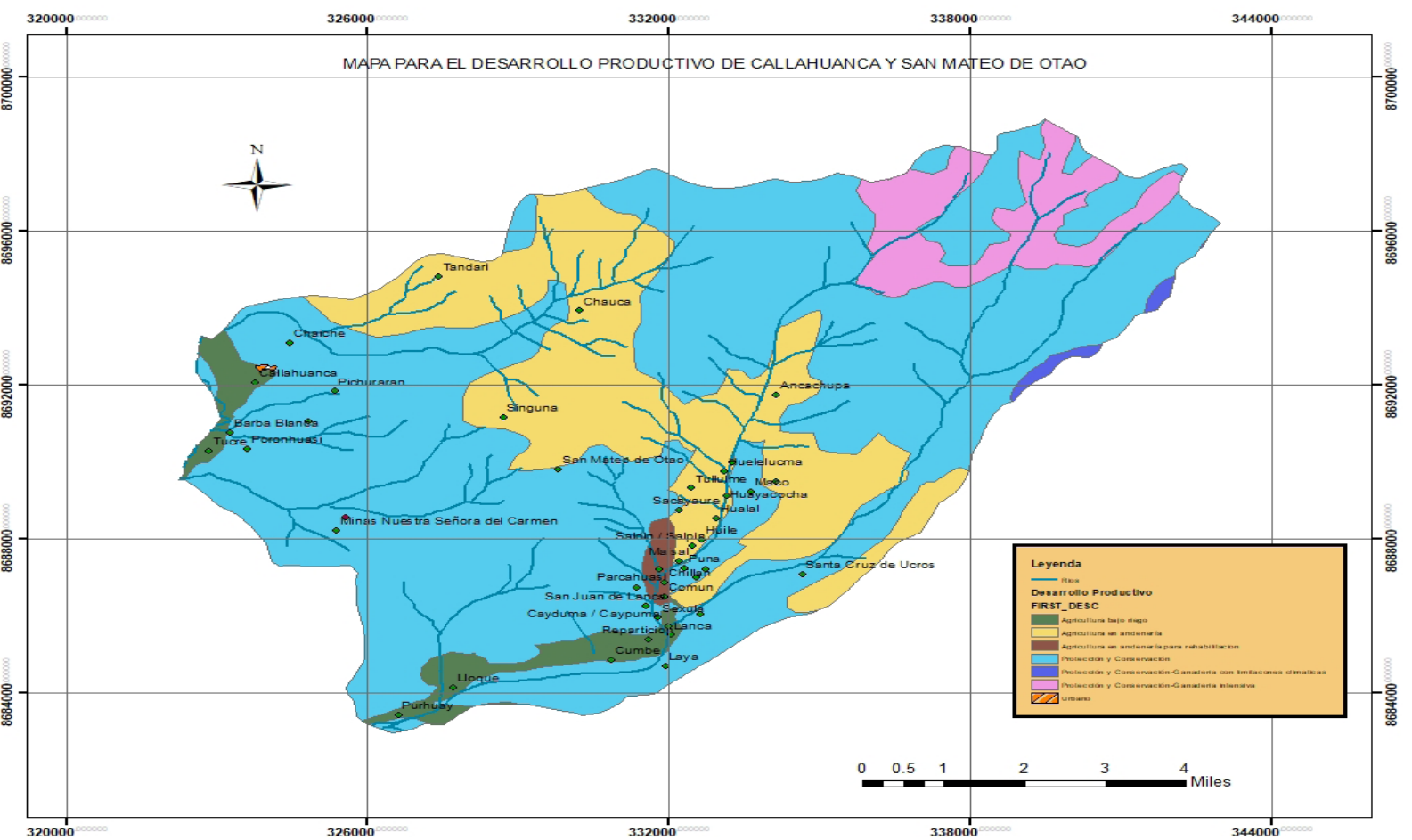

Fuente. IGN-Elaboración propia. 
Gráfico 1. Callahuanca: Población: 1981-2015

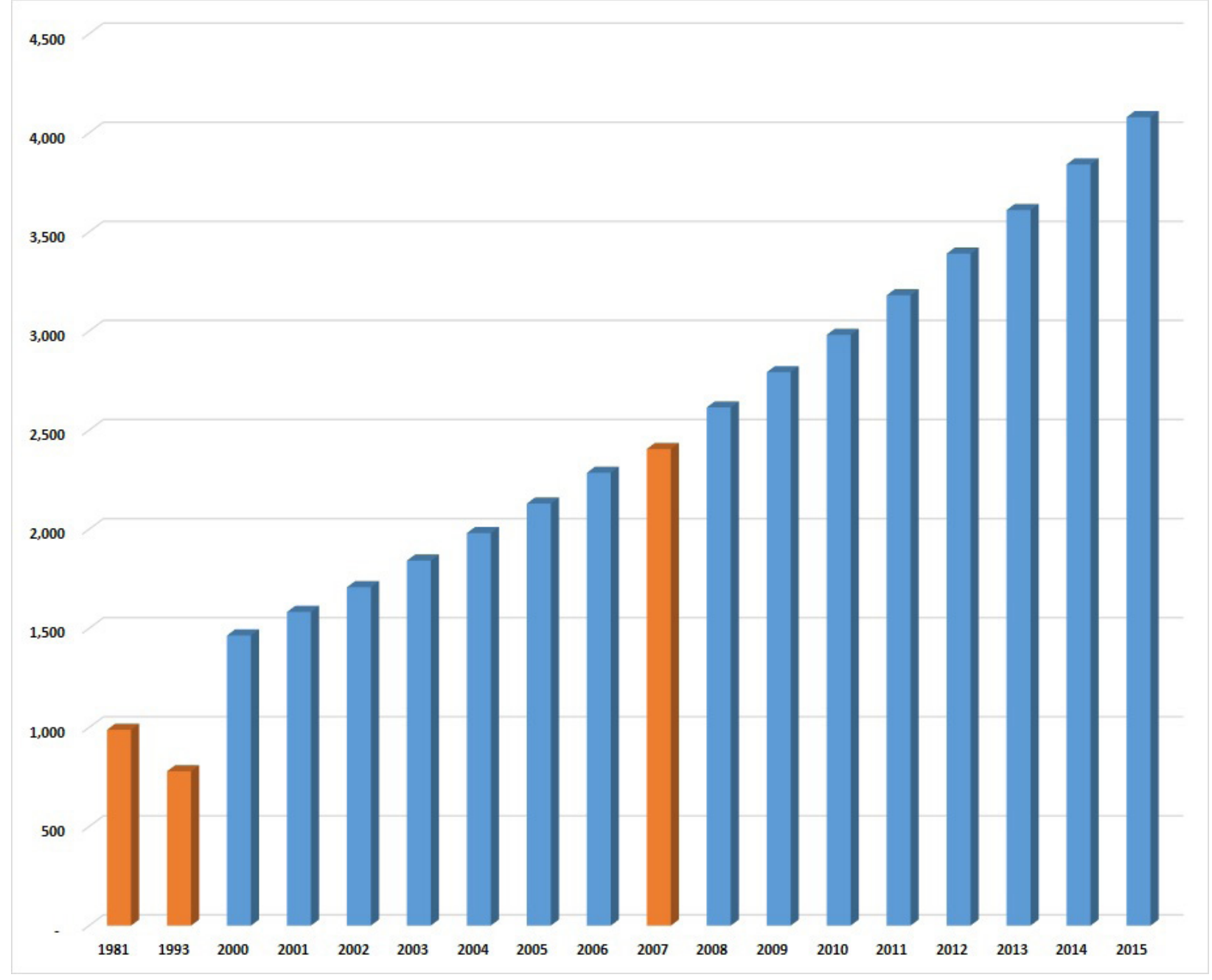

Fuente: INEI - Censos Nacionales de 1981, 1993 y 2007 \& INEI - Población estimada por años calendario: 2000 - 2015. Años censales.

cultural de la nación por el Instituto Nacional de Cultura, mediante Resolución Directoral Nacional N. 620 /INC, del Lima, 12 de mayo de 2005. El sitio arqueológico de Marca Marca se encuentra en el cerro Curimacas, a una altura de $2780 \mathrm{msnm}$., frente del pueblo de Canchacalla. Chaupimarca se encuentra en Purhuay, anexo de Cumbe, a una altura de $1350 \mathrm{msnm}$, en la cima del cerro del mismo nombre. Las estructuras están conectadas por caminos los que han sido restaurados, lo que ha disturbado su forma y hace difícil determinar el acceso original. Huarichaca (puente de los Wari; Sol Sagrado) está ubicada al norte del actual pueblo de San Mateo de Otao, en el cerro Huarichaca a $3880 \mathrm{msnm}$, en las coordenadas $76^{\circ} 38^{\prime}$ longitud Oeste y $11^{\circ} 30^{\prime}$ latitud Sur, a una elevación de 100 metros del pueblo de San Mateo de Otao.

\section{Distrito: Santa Rosa de Callahuanca}

Callahuanca, del quechua cajlla y huanca, significa "piedra grande». Fue creado mediante Ley N. ${ }^{\circ} 12825$ del 12 de abril de 1957, en el segundo gobierno del Presidente Manuel Prado Ugarteche. El nombre completo del distrito es Santa Rosa de Callahuanca, siendo Santa Rosa de Lima patrona del distrito y a la cual se le venera el 30 de agosto. El pueblo de Callahuanca comprende además los anexos de San Pedro de Chauca y Barbablanca, así como los caseríos de Purunhuasi y San José de Tucre. Está ubicado en 
la provincia de Huarochirí, Región Lima, a dos horas de la capital.

A $5 \mathrm{~km}$ de Callahuanca, en Barba Blanca, se encuentra el sitio arqueológico de Cascashoko. Es una zona arqueológica amurallada compuesta por estructuras preincaicas, con casas con base de piedra, probablemente una ciudadela de gran importancia.

\section{Características demográficas}

\section{Distrito: Santa Rosa de Callahuanca}

Los datos censales nos indican que la población de Callahuanca fue disminuyendo paulatinamente como consecuencia de la migración interna en el censo de 1981 figuran 988 habitantes y en el de 1993, 779 habitantes; recién en el 2000 se produce un incremento a 1464 habitantes y a partir de este año la población en este distrito ha ido aumentando constantemente en 2015 es de 4080 habitantes; cómo se puede apreciar en el Cuadro 2 y Gráfico 1. La tasa de crecimiento anual, en promedio se elevó a $6.9 \%$; este factor se explica por el desarrollo social alcanzado a diferencia de otros distritos vecinos.

$\mathrm{Al}$ comparar los gráficos 02 y 03 podemos encontrar las diferencias en la estructura poblacional en

Gráfico 2. Callahuanca: Pirámide Poblacional 1981

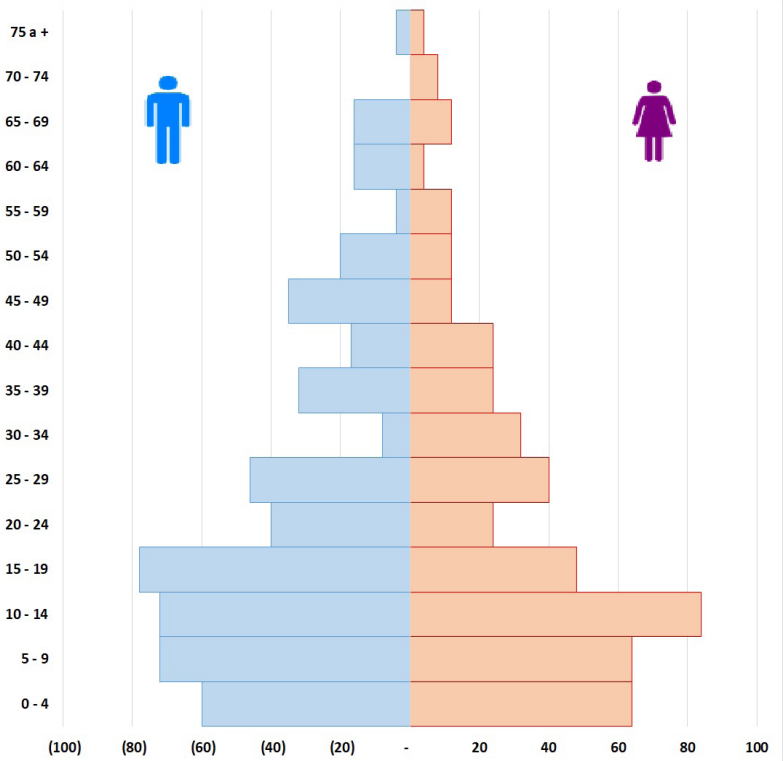

Fuente: INEI. Censos Nacionales 1981
Cuadro 2

Callahuanca: Población según sexo e Índice de Masculinidad: 1981-2015

\begin{tabular}{|c|c|c|c|c|}
\hline Ańo & Total & Hombre & Mujer & Ind. Mascul. \\
\hline $1981 / \mathrm{a}$ & 988 & 520 & 468 & 1.11 \\
\hline $1993 / \mathrm{a}$ & 779 & 432 & 347 & 1.24 \\
\hline 2000 & 1,464 & 781 & 683 & 1.14 \\
\hline 2001 & 1,583 & 839 & 744 & 1.13 \\
\hline 2002 & 1,708 & 899 & 809 & 1.11 \\
\hline 2003 & 1,842 & 963 & 879 & 1.10 \\
\hline 2004 & 1,981 & 1,029 & 952 & 1.08 \\
\hline 2005 & 2,130 & 1,099 & 1,031 & 1.07 \\
\hline 2006 & 2,285 & 1,171 & 1,114 & 1.05 \\
\hline $2007 / \mathrm{a}$ & 2,405 & 1,224 & 1,181 & 1.04 \\
\hline 2008 & 2,615 & 1,323 & 1,292 & 1.02 \\
\hline 2009 & 2,793 & 1,404 & 1,389 & 1.01 \\
\hline 2010 & 2,981 & 1,489 & 1,492 & 1.00 \\
\hline 2011 & 3,181 & 1,579 & 1,602 & 0.99 \\
\hline 2012 & 3,391 & 1,674 & 1,717 & 0.97 \\
\hline 2013 & 3,611 & 1,772 & 1,839 & 0.96 \\
\hline 2014 & 3,841 & 1,874 & 1,967 & 0.95 \\
\hline 2015 & 4,080 & 1,980 & 2,100 & 0.94 \\
\hline & & & & \\
\hline
\end{tabular}

Fuente: INEI - Censos Nacionales de 1981, 1993 y 2007 \& INEI Población estimada por años calendario: 2000-2015

a/ Ańos censales.

GrÁfico 3. Callahuanca: Pirámide Poblacional 2007

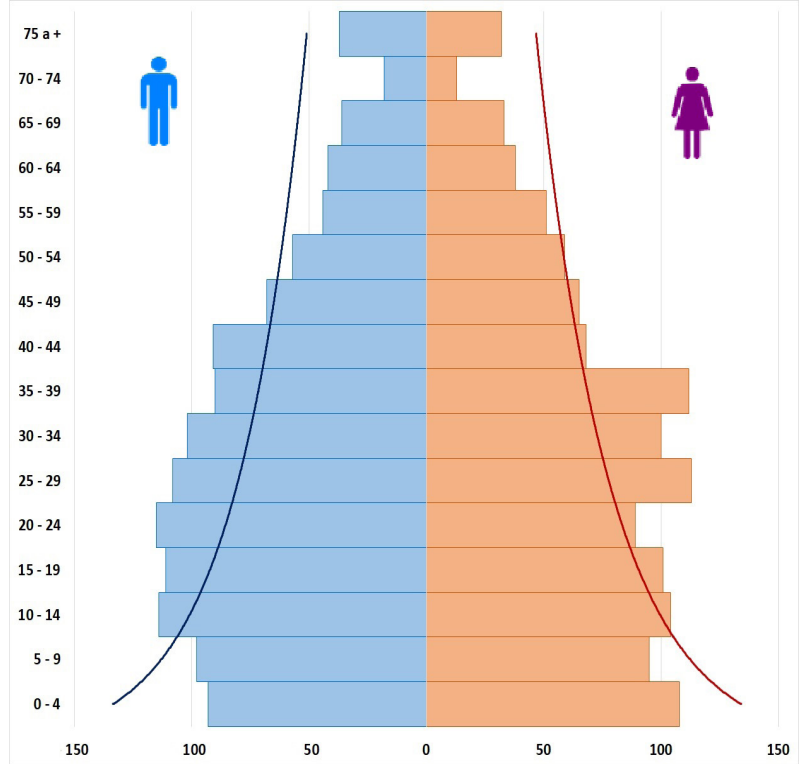

Fuente: INEI. Censos Nacionales 2007 
los años censales de 1981 y 2007. Se nota un crecimiento proporcional de la población masculina y femenina por el efecto inmigratorio a la comunidad de Callahuanca, debido al desarrollo socioeconómico (agricultura, comercio y turismo). Los adultos mayores de 75 y más años se quedan para dedicarse al pequeño comercio y al descanso disfrutando del clima agradable y la tranquilidad de la zona.

\section{San Mateo de Otao}

La población del distrito de San Mateo de Otao, se encuentra en la margen derecha del río Rímac y ha tenido un desarrollo demográfico muy común a los lugares rurales de nuestro país. Los datos censales, así como de las proyecciones de población, nos indican que la población ha ido disminuyendo paulatinamente como consecuencia de la migración.

Según la distribución por sexo, se observa en el cuadro 3 mayor número de población masculina, debido a la migración selectiva por sexo es decir, emigraronn más las mujeres en comparación a los hombres, esto se ve en los índices de masculinidad de 120 hombres por 100 mujeres en el año 1993 , y 112
Cuadro 3

San Mateo de Otao: Población según sexo e Índice de Masculinidad: 1981-2015

\begin{tabular}{|c|c|c|c|c|}
\hline Año & Total & Hombre & Mujer & Ind. Mascul. \\
\hline $1981 / \mathrm{a}$ & 2,407 & 1,225 & 1,182 & 104 \\
\hline $1993 / \mathrm{a}$ & 2,062 & 1,123 & 939 & 120 \\
\hline 2000 & 2,108 & 1,120 & 988 & 113 \\
\hline 2001 & 2,088 & 1,104 & 984 & 112 \\
\hline 2002 & 2,066 & 1,087 & 979 & 111 \\
\hline 2003 & 2,041 & 1,069 & 972 & 110 \\
\hline 2004 & 2,013 & 1,049 & 964 & 109 \\
\hline 2005 & 1,984 & 1,029 & 955 & 108 \\
\hline 2006 & 1,951 & 1,007 & 944 & 107 \\
\hline $2007 / \mathrm{a}$ & 1,915 & 984 & 931 & 106 \\
\hline 2008 & 1,877 & 960 & 917 & 105 \\
\hline 2009 & 1,839 & 936 & 903 & 104 \\
\hline 2010 & 1,801 & 913 & 888 & 1.03 \\
\hline 2011 & 1,762 & 889 & 873 & 1.02 \\
\hline 2012 & 1,723 & 866 & 857 & 101 \\
\hline 2013 & 1,684 & 843 & 841 & 100 \\
\hline 2014 & 1,643 & 819 & 824 & 099 \\
\hline 2015 & 1,603 & 796 & 807 & 099 \\
\hline
\end{tabular}

Fuente: INEI - Censos Nacionales de 1981, 1993 y 2007 \& INEI Población estimada por años calendario: 2000 - 2015. a/ Años censales.

Gráfico 4. San Mateo de Otao: Población: 1981-2015

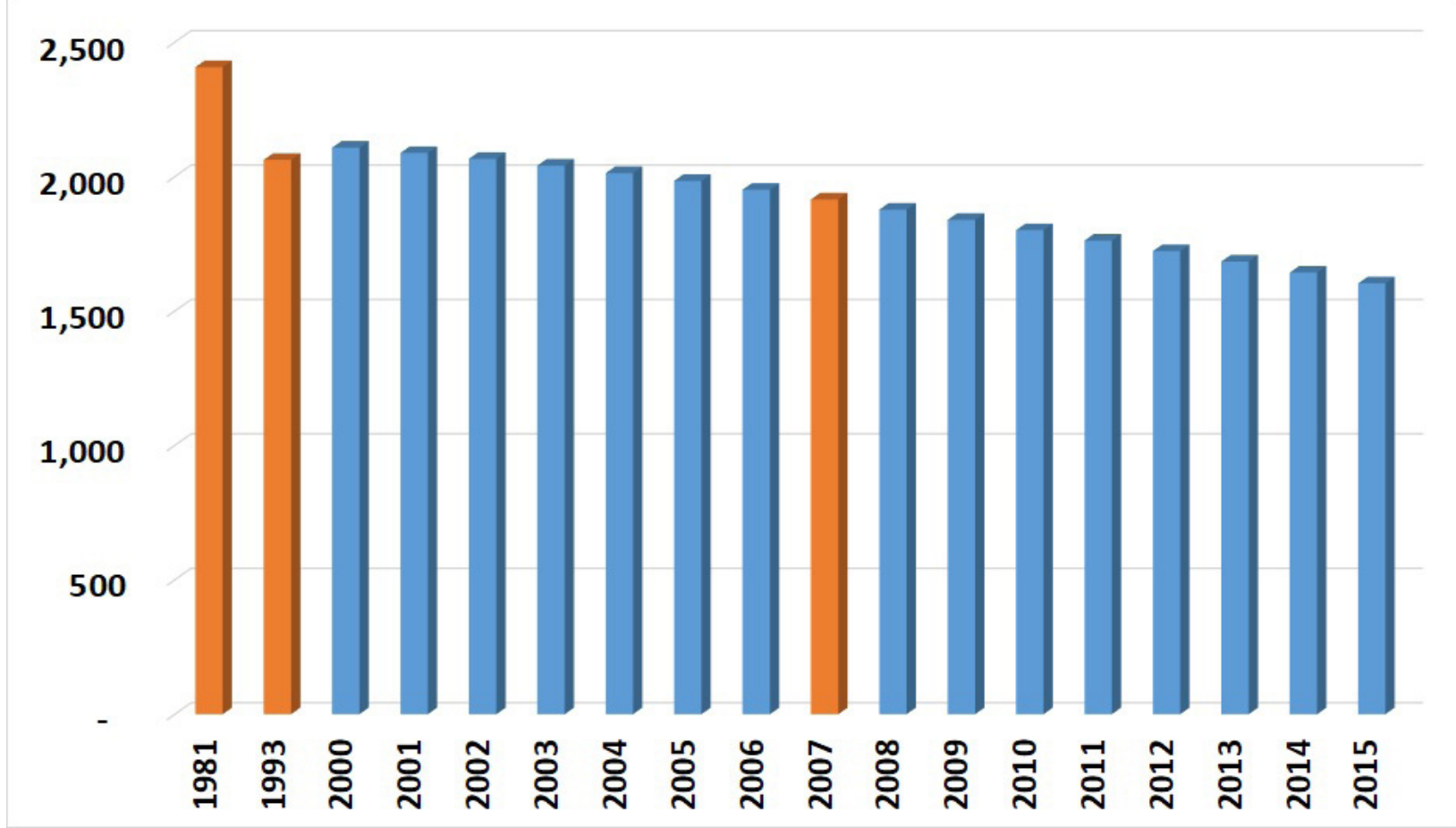

Fuente: INEI - Censos Nacionales de 1981, 1993 y 2007 \& INEI - Población estimada por años calendario: 2000 - 2015. Ańos censales. 
Gráfico 5. San Mateo de Otao: Pirámide Poblacional 1981

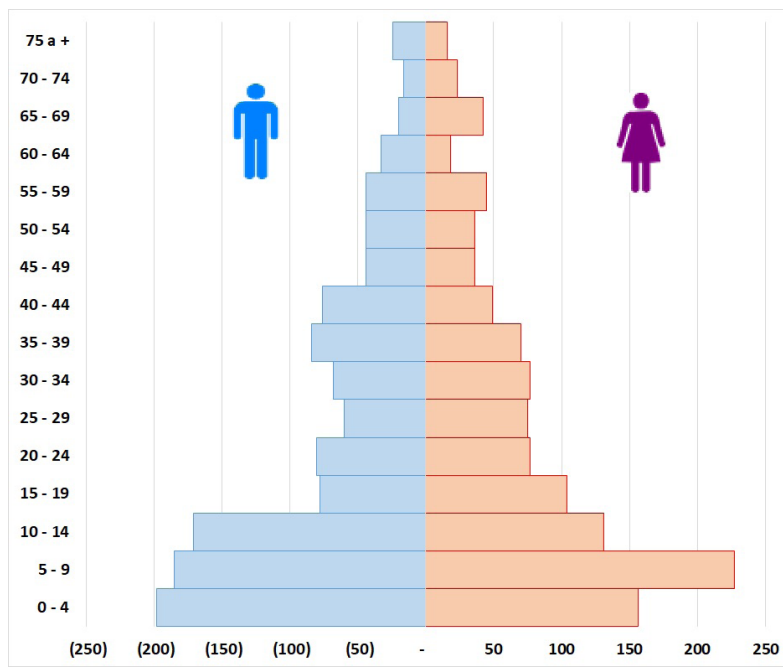

Fuente: INEI. Censos Nacionales 1981.

hombres por 100 mujeres en el 2001. Pero a partir de 2014 se invierte esta dinámica con la presencia de más mujeres en la comunidad, 99 hombres por 100 mujeres.

Como podemos ver en el Cuadro 3 y en el Gráfico 4, la población del distrito de San Mateo de Otao ha ido decreciendo constantemente en los últimos años. La tasa de crecimiento anual, en promedio es de $-1,7 \%{ }^{4}$. Este factor es explicado por las limitaciones en el desarrollo social y emigración a diferencia de otros distritos vecinos.

Según la estructura poblacional 1981 de la pirámide vemos que en San Mateo de Otao permanecen los jóvenes menores de 14 años y los adultos mayores de 65. Los jóvenes partir de los 15 años salen del distrito, hombres y mujeres casi en la misma proporción.

Las proporciones estructurales de la pirámide presenta un distrito receptor de población en las edades 20 a 34 ańos y expulsor en grupos etareos subsiguiente; pero hay una migración de retorno de los mayores de 75 años. La migración de los jóvenes ocasiona la perdida de mano de obra para el trabajo en la agricultura.

4 Si contrastamos este dato distrital con la tasa de crecimiento poblacional a nivel nacional veremos que existe un gran diferencia, Tasa Nacional de Crecimiento: $1.6 \%$ anual.
Gráfico 6. San Mateo de Otao: Pirámide Poblacional 2007

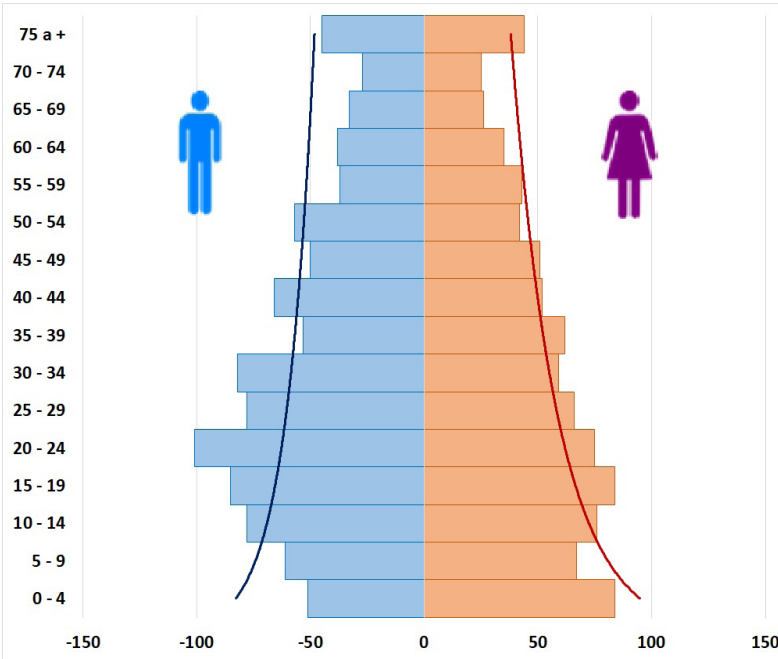

Fuente: INEI. Censos Nacionales 2007.

Cuadro 4

Cambios de la Población de Callahuanca y San Mateo de Otao, 1981-2016

\begin{tabular}{|c|c|c|}
\hline AÑOS & CALLAHUANCA & $\begin{array}{c}\text { SAN MATEO DE } \\
\text { OTAO }\end{array}$ \\
\hline 1981 & 988 & 2407 \\
\hline 1993 & 779 & 2062 \\
\hline 2000 & 1464 & 2108 \\
\hline 2001 & 1583 & 2088 \\
\hline 2002 & 1708 & 2066 \\
\hline 2003 & 1842 & 2041 \\
\hline 2004 & 1981 & 2013 \\
\hline 2005 & 2130 & 1984 \\
\hline 2006 & 2285 & 1951 \\
\hline 2007 & 2405 & 1833 \\
\hline 2008 & 2615 & 1877 \\
\hline 2009 & 2793 & 1839 \\
\hline 2010 & 2981 & 1801 \\
\hline 2011 & 3181 & 1762 \\
\hline 2012 & 3391 & 1723 \\
\hline 2013 & 3611 & 1684 \\
\hline 2014 & 3841 & 1643 \\
\hline 2015 & 4080 & 1603 \\
\hline 2016 & 4184 & 1589 \\
\hline $1 N E$ & 2007 & \\
\hline
\end{tabular}

Fuente: INEI 1981,1993 y 2007 y estimación 2000-2016.

Finalmente, las referencias estadísticas muestran que ambas localidades tuvieron un comportamiento evolutivo diferente, mientras Callahuanca presenta 
Gráfico 7. Callahuanca, Otao: Cambios poblacionales, 1981-2016

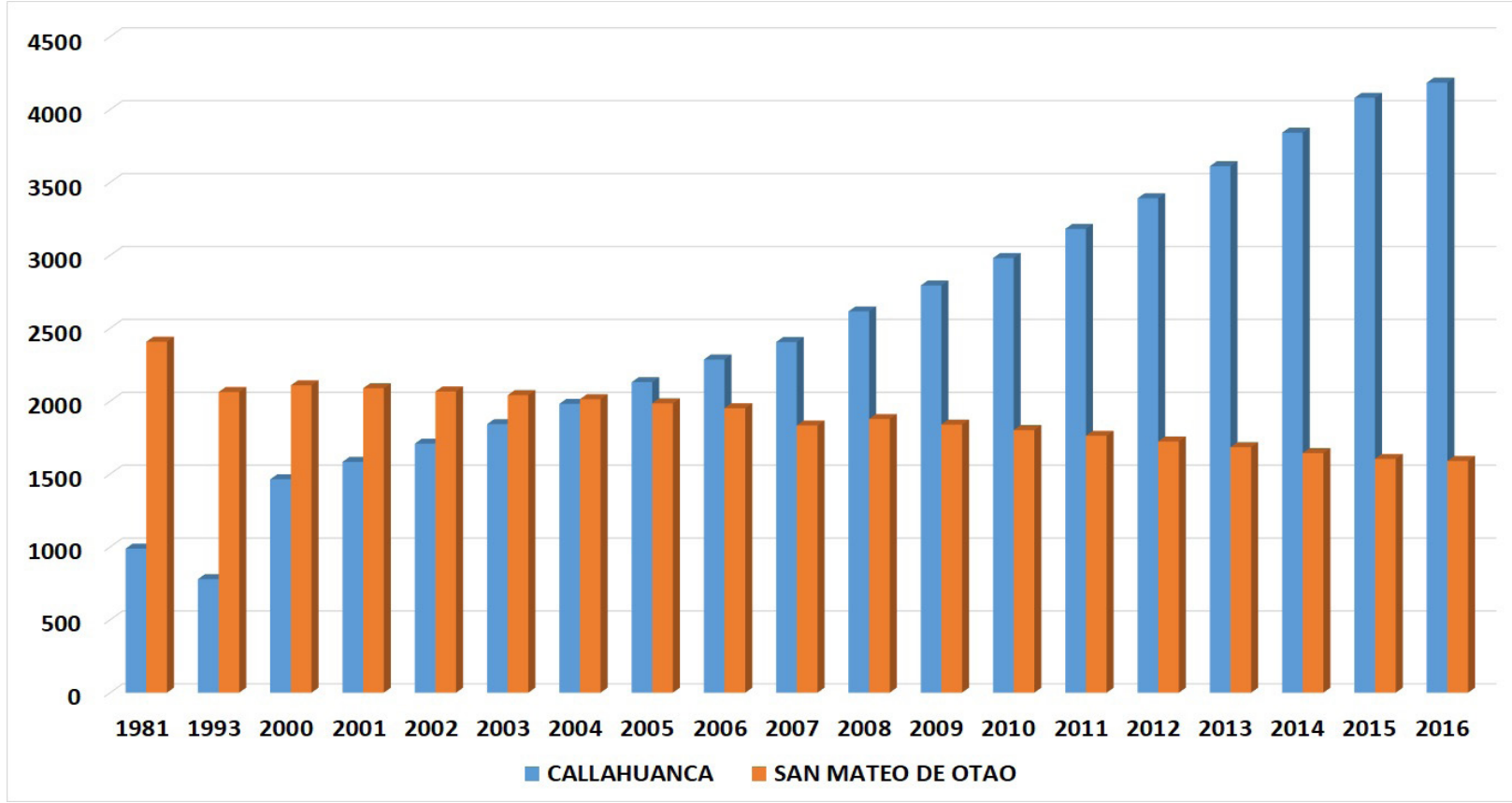

Fuente: INEI

Gráfico 8. Callahuanca, Otao: Evolución de Densidad Poblacional, 1981-2016

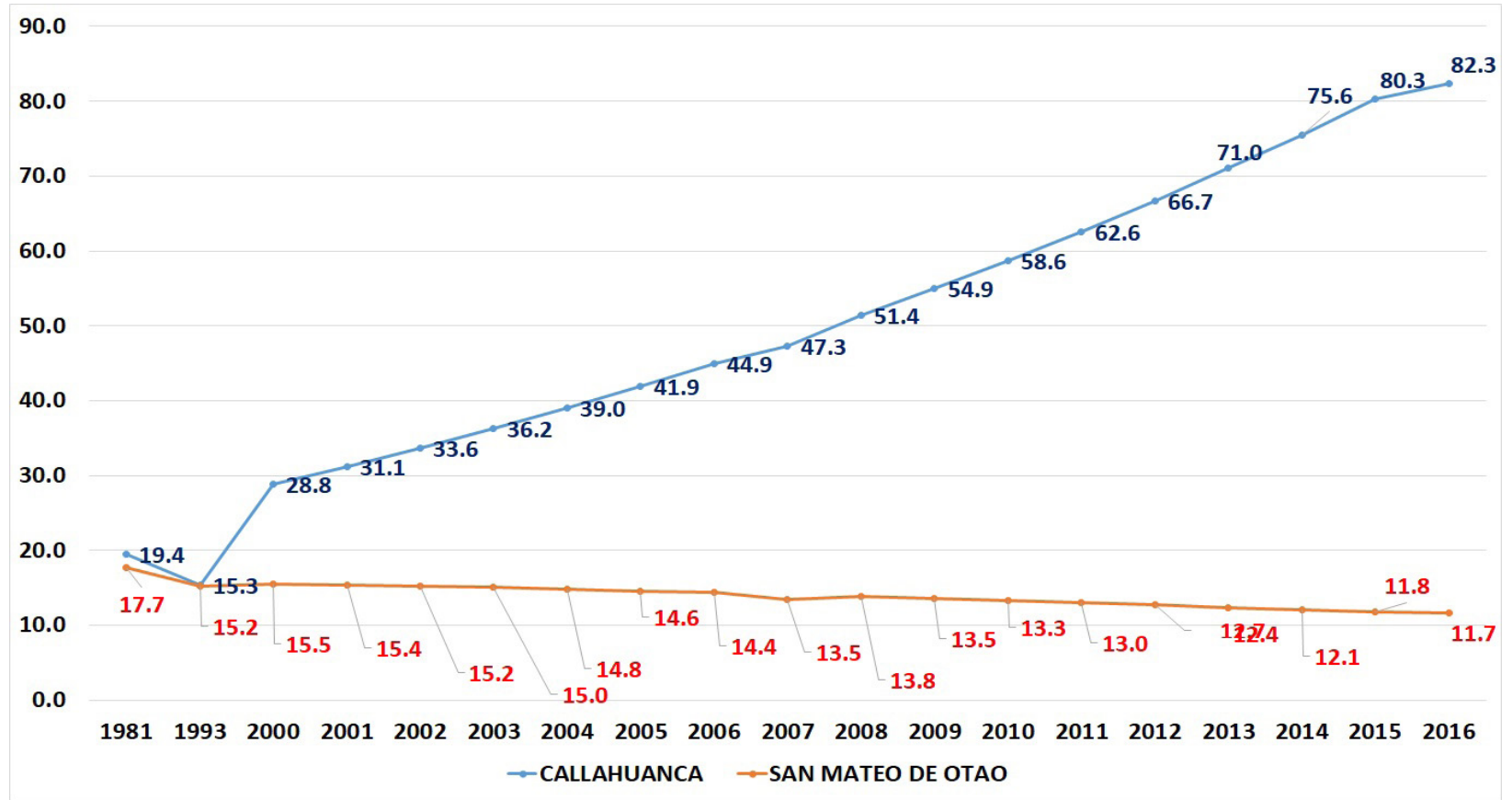

Fuente: INEI.

un decrecimiento entre 1981 a 1993, en los siguientes años la población va en aumento alcanzando a 4184 en el 2016, pobladores como resultado de la migración a la zona para los trabajos agrícolas. San
Mateo de Otao, en cambio, fue decreciendo, como resultado de la migración (Ver cuadro 4 y Gráfico 7).

Las densidades de la población entre Callahuanca y San Mateo de Otao son muy diferentes, en San 
Mateo de Otao es de 11.7 habitantes por $\mathrm{km}^{2}$ (2016), mientras que en Callahuanca es de 82.3 habitantes por $\mathrm{km}^{2}$.

\section{Movimientos migratorios}

Las estadísticas censales muestran a la provincia de Huarochiri, donde están ubicados los distritos de Callahuanca y Otao, como expulsora de población. Entre 1988-1993 (migración reciente hace cinco años) salieron de la provincia 15028 e ingresaron (inmigrantes) 8,085 personas. Los datos del 2007 para la migración reciente (2002-2007) manifiesta la misma dinámica pero con más intensidad 57415 emigrantes y 7710 inmigrantes con un saldo migratorio negativo de $-49,705$, es decir Huarochiri pierde población por efectos de la migración. Estos distritos se caracterizan también por ser expulsores y receptores de población. Callahuanca, entre el 81y el 93 fue expulsora, de ahí en adelante la dinámica poblacional se invierte convirtiéndose en receptora de población. Los jóvenes emigran hacia la capital Lima Metropolitana. Los que se quedan son los padres que generalmente son adultos mayores. Callahuanca se destaca por la presencia de huancavelicanos que migran con la finalidad de trabajar en la agricultura. En San Mateo de Otao se observa una dinámica diferente, los datos muestran que el distrito es expulsor de población, pero, según las entrevistas a inmigrantes y a lugareños, la migración es temporal y se presenta en las temporadas de cultivo y cosecha y en obras temporales de infraestructura.

\section{Situación de la salud e indicadores más relevantes}

Tal como informa la Dirección Regional de Salud del Gobierno Regional de Lima en el Análisis de Situación de Salud 2017 Región Lima, «La Provincia (de Huarochirí) tiene varios pisos altitudinales entre 56 a $2398 \mathrm{msnm}$ y condiciones ambientales diferentes en cada uno de ellos, cuentan con 32 distritos con una población estimada en 102310 habitantes y un número de viviendas de superior a $30,000 \ldots$ Esta situación favorece a la dispersión de diferentes vectores de interés en la salud Pública, es así que la presencia de Triatominos del Genero Triatoma sp se ha reportado en el distrito... El vector Aedes aegypti, transmisor de la enfermedad del Dengue hasta el primer trimestre

Gráfico 9. Huarochirí: Recursos Humanos en Salud, 2017

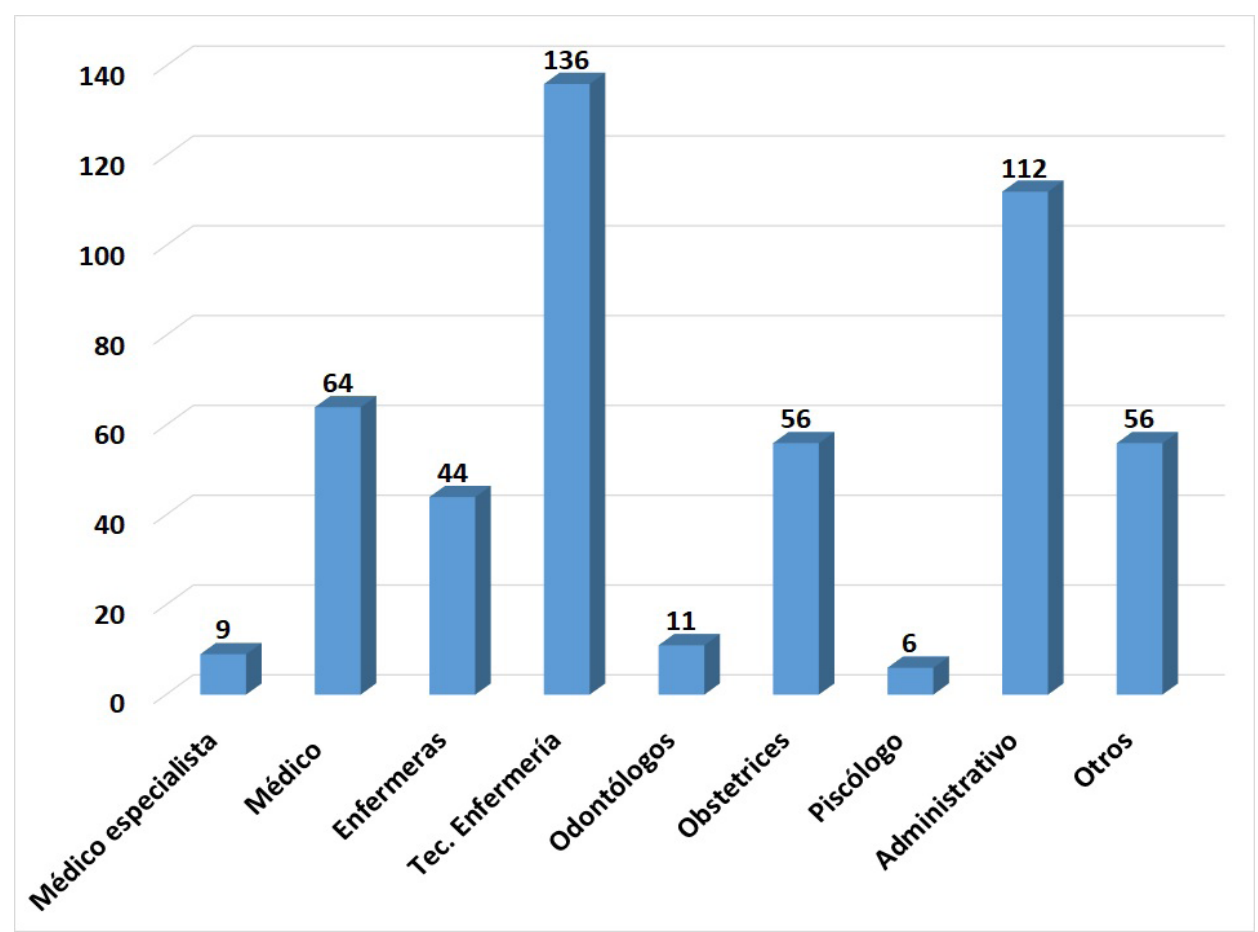

Fuente: DIRESA - Gobierno Regional Lima: Análisis de la Situación de Salud en Huarochirí, 2017. 
del 2015 estuvo considerado como el único escenario II de la DIRESA Lima, por estar en la mayoría de las localidades..."

El Gobierno Regional Lima, en el informe: Análisis de la Situación de la salud en la provincia de Huarochirí, dice: «La Red de Salud Huarochirí con una población de 79.944 habitantes, distribuida en cinco Micro Redes y un hospital con un total de 68 establecimientos de Salud, según el número de personal por grupo ocupacional no (se) abastece para cubrir las necesidades de servicios de Salud, por lo que requiere una gestión de requerimiento de Recursos Humanos y la distribución de los mismos en zonas vulnerables como las zonas rurales».

Si bien es cierto que la Red de Salud de Huarochirí cuenta con 68 establecimientos en toda su jurisdicción, entre puestos de salud (postas), Centros de Salud y un Hospital (ubicado en la capital de la provincia: Matucana), en el distrito de Callahuanca solo cuentan con un Puesto de Salud (ubicado en la plaza de armas del distrito). En el distrito de San Mateo de
Otao se cuenta con cuatro puestos de salud, uno en el anexo de Cumbe, otro en Lanca, otro en Tapicara y otro en Canchacalla.

Cuando la población entiende que el problema de salud no es complicado se atiende en uno de esos puestos de Salud, en casos más complicados prefieren ir a otras dependencias de salud ubicadas en Santa Eulalia, Chosica y Lima Metropolitana. Sobre el sistema integral de salud (SIS), según el INEI, en julio de 2016 estaban en este sistema de seguro 95 menores de 4 años y 998 mayores de 5 años, de estos 503 del sexo femenino y 495 del sexo masculino.

\section{Desnutrición crónica}

La desnutrición crónica es una variable que está asociada directamente a la pobreza. De acuerdo a informes permanentes de INEI los indicadores de la desnutrición en niños menores de 5 años se han modificado de la siguiente manera:

Gráfico 10. Callahuanca: Evolución de número de docentes, 2004-2017

30

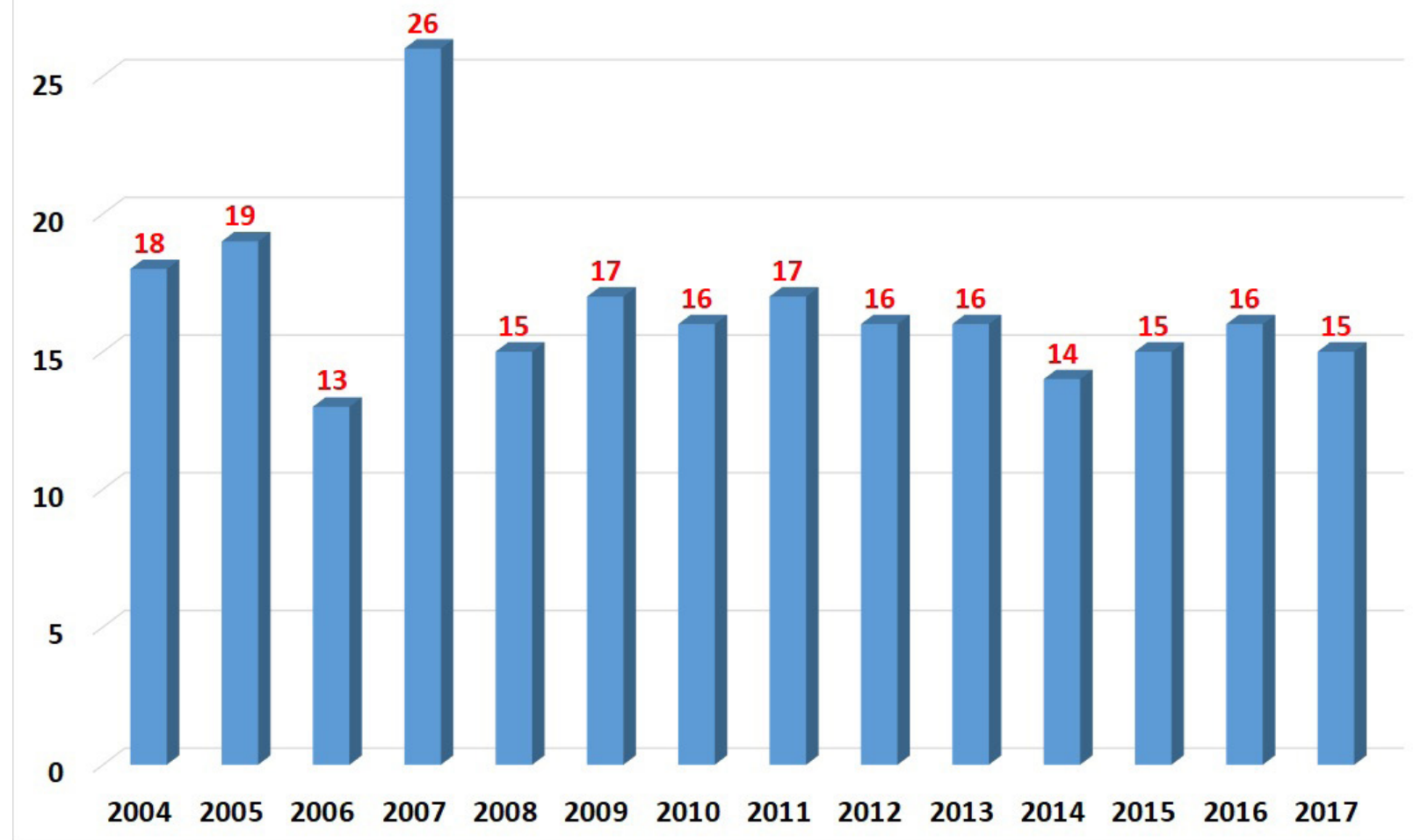

Fuente: Sitio Web: ESCALE - Estadísticas de la Calidad Educativa. 


\section{Cuadro 5}

Callahuanca, San Mateo de Otao: Desnutrición Infantil, 2007, 2009 y 2017

\begin{tabular}{|l|c|c|c|}
\hline & 2007 & 2009 & 2017 \\
\hline Callahuanca & 48.5 & 29.0 & 4.5 \\
\hline San Mateo de Otao & 34.4 & 24.4 & 20.4 \\
\hline
\end{tabular}

Fuente: Minsa - Perú, Indicadores nutricionales en niños, 2017.

Las niñas y niños con desnutrición crónica tienen una serie de problemas en su salud: anemia, rendimiento escolar bajo, etc.

\section{La educación}

El fenómeno educativo es una variable determinante para el desarrollo de una comunidad.

En cuanto a las estadísticas de los servicios educativos en los distritos estudiados, encontramos datos interesantes. Pero concluimos que los servicios educativos, en cuanto a niveles de Inicial, Primaria y
Secundaria, están en un claro declive debido a la disminución de la población, como efecto del fenómeno migratorio, como podemos ver en los gráficos 10, 11, 12 y 13. En el distrito de San Mateo de Otao, la población está disminuyendo y es lógico que los servicios educativos, en esos niveles, también disminuyan. En el distrito de Callahuanca, en cambio, a pesar de que la población está creciendo (tasa de crecimiento: $6.2 \%$ en promedio en los últimos 10 años), se puede ver a partir de la pirámide poblacional que los quinquenios de personas mayores de 15 ańos son las que están aumentando, la única explicación posible para esto es la migración de población joven, adulta joven o adulta.

\section{Discusión}

En base a toda la información recabada encontramos dos distritos vecinos: Callahuanca y San Mateo de Otao, con similares características pero con diferente

GrÁfico 11. Callahuanca: Evolución de número de estudiantes, 2004-2017

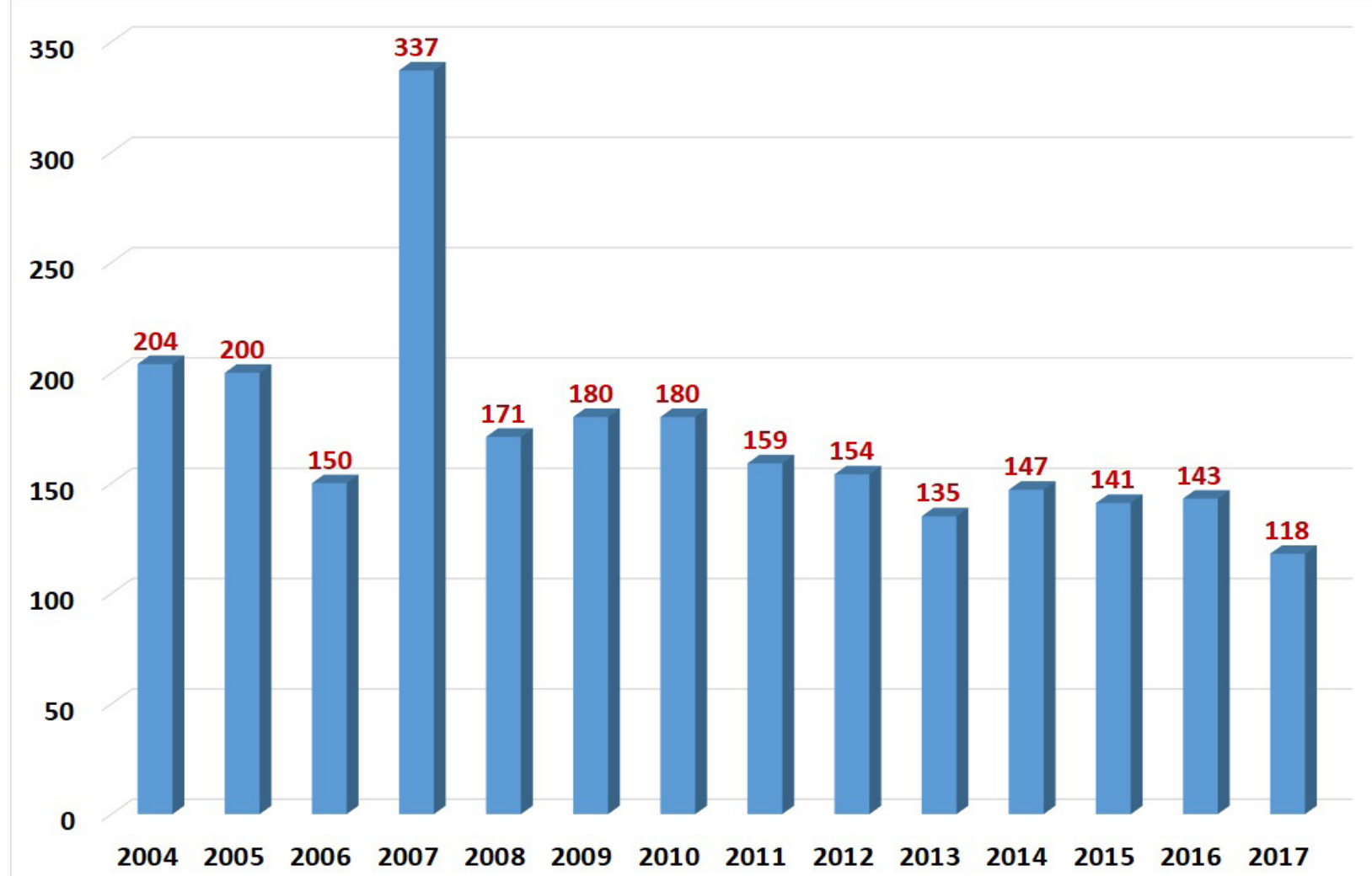

Fuente: Sitio Web: ESCALE - Estadísticas de la Calidad Educativa. 
Gráfico 12. San Mateo de Otao: Evolución de número de docentes, 2004-2017

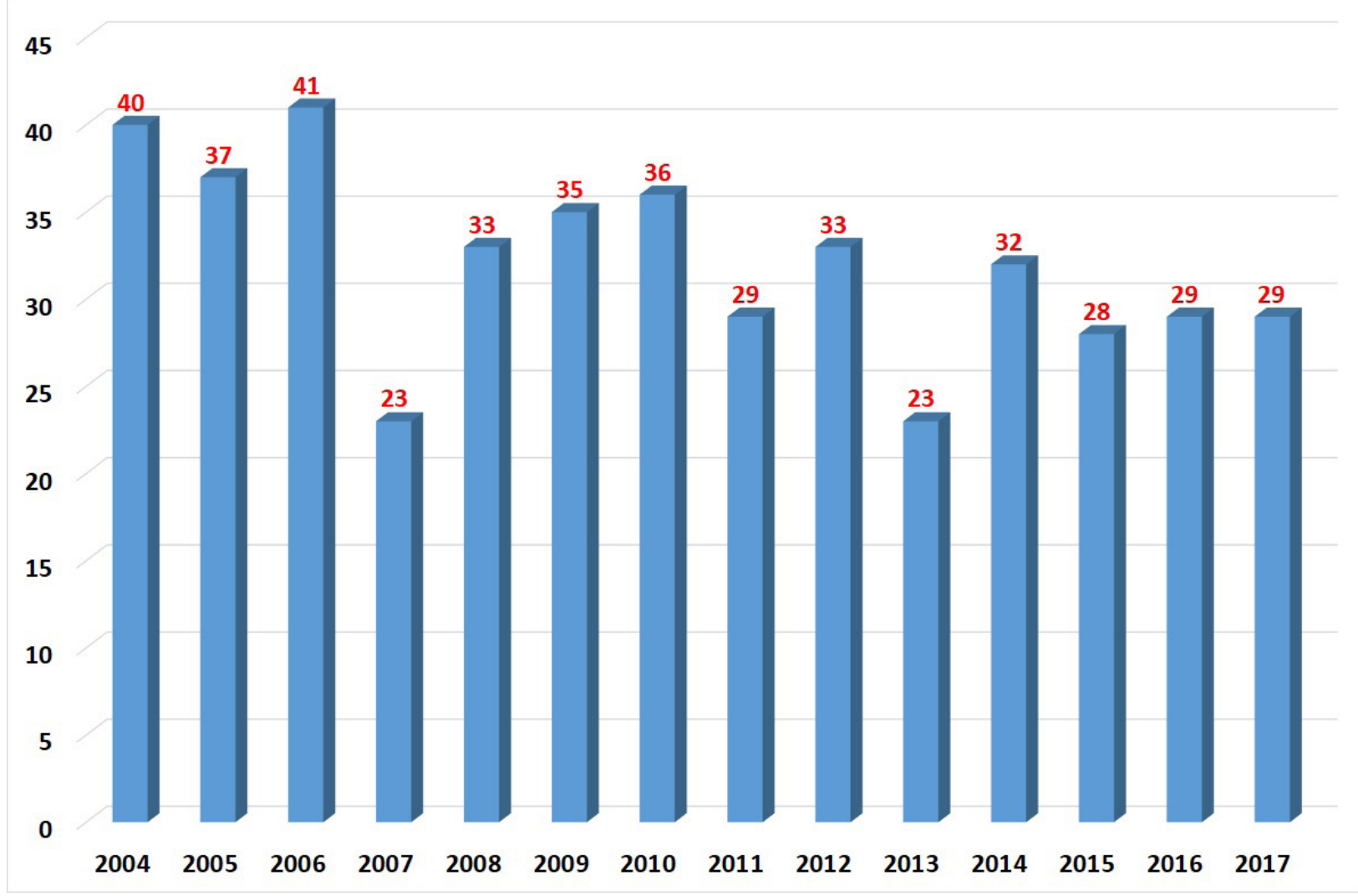

Fuente: Sitio Web: ESCALE - Estadísticas de la Calidad Educativa.

desarrollo social. Poseen recursos naturales de fauna, flora, minerales y agua, que deben ser utilizados y canalizados previo estudio específico del área, para poder generar el desarrollo sostenible en aras del bienestar de la población. Callahuanca está aprovechando sus recursos para generar un desarrollo económico y comercial, a partir de la producción agrícola de exportación, lo cual genera atractivo para la migración laboral. San Mateo de Otao, en cambio, se encuentra en un proceso de desarrollo agrícola de paltas, chirimoyas, etc.

Para aumentar la extensión de áreas cultivadas, es necesario la construcción de represas para almacenar el agua de la estación de lluvia en las microcuencas, a fin de regar las hectáreas improductivas que corresponden a andenerías ancestrales y de este modo aumentar la producción de chirimoyas y paltos, etc. Esto incentivaría a los productores la inversión en centros industriales para dar valor agregado a los productos regionales con el objetivo de generar empleo para la juventud y evitar la migración. Paralelamente, promover la capacitación de los jóvenes lugareños con carreras técnicas relacionadas con la agricultura, ganadería, transformación de productos, etc., con la finalidad de que los jóvenes se queden en el pueblo.

Las zonas arqueológicas son de gran valor histórico y cultural, y deben ser puestas en valor y conservadas por el Ministerio de Cultura y el gobierno regional, en coordinación con las autoridades locales promoviendo la investigación y el turismo. Se debería canalizar su estudio y puesta en valor a partir de alianzas estratégicas con las universidades que se encargarían de su prospección, estudio y, posterior, puesta en valor para la comunidad. Además los distritos poseen zonas atractivas para el turismo de aventura, vivencial y ecológico, los cuales también tendrían que ser optimizadas, promovidas y difundidas ${ }^{5}$ para el bien de la comunidad.

5 A partir de programas organizados por las autoridades locales y principalmente a través de las redes sociales que permitirían una rápida difusión. 
Gráfico 13. San Mateo de Otao: Evolución de número de estudiantes, 2004-2017

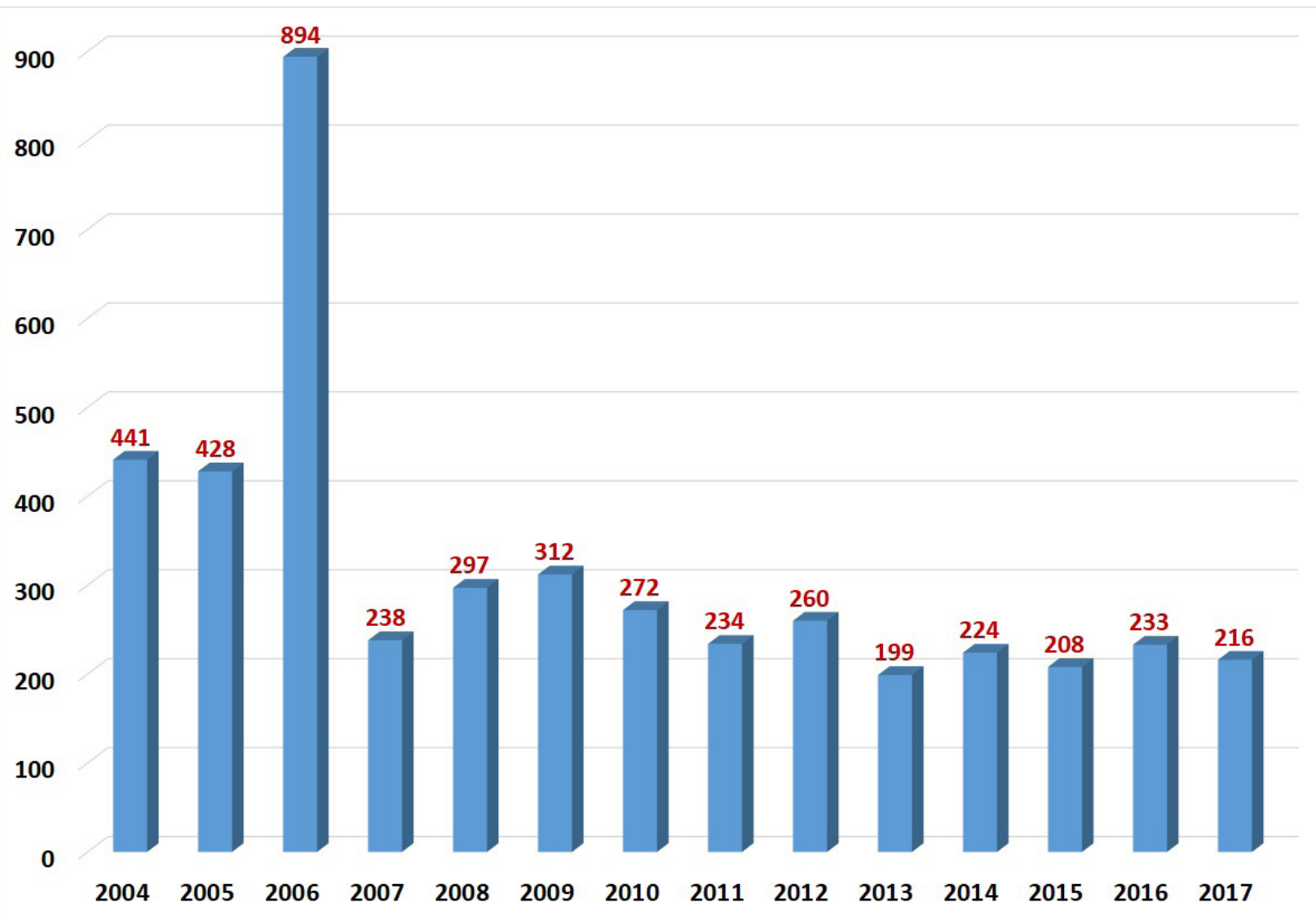

Fuente: Sitio Web: ESCALE - Estadísticas de la Calidad Educativa.

Gestionar la ejecución, con el apoyo de los gobiernos locales y regionales, de la construcción de las carreteras entre los pueblos y anexos en San Mateo de $\mathrm{Otao}^{6}$, con la finalidad de promover el turismo para un desarrollo endógeno. Dotar a los centros educativos de infraestructura adecuada (aulas, bibliotecas, laboratorios, canchas deportivas, etc.), para que los niños puedan aprender mejor. La implementación de los programas sociales de los desayunos y almuerzos a los niños y niñas para reducir la desnutrición, logrando un mejor aprendizaje y evitando la deserción escolar.

Los puestos de salud del Minsa ponen a disposición de la población el personal asistencial disponible. Las limitaciones son patentes: horarios insuficientes, al igual que el personal médico especializado; no hay medicamentos al alcance de las necesidades

6 La carretera asfaltada que ingresa a Callahuanca se encuentra en buen estado, a pesar de los estragos de los huaicos del año 2017. de la población, etc. Estos problemas deben ser superados con la finalidad de evitar que estos salgan a otros lugares buscando una mejor atención. A los niños menores de cinco ańos debe dárseles un tratamiento especial con los controles de talla y peso, promoviendo la capacitación de las madres en educación alimentaria para superar la desnutrición crónica variable asociada directamente con la pobreza. Los distritos poseen recursos para destinarlos a combatir la desnutrición que daña la salud de los infantes, limita el aprendizaje y determina su futuro disminuyendo sus funciones psicomotoras, cognitivas, laborales y productivas.

Según los datos del INEI, la provincia de Huarochirí y, especialmente, distritos como San Mateo de Otao son expulsores de población, por tal razón el gobierno regional debe adoptar medidas descentralizadas y generar el desarrollo socioeconómico y el bienestar en las zonas rurales de estos distritos. Las autoridades locales son los encargados de iden- 
tificarse con la problemática de los distritos en todos los ámbitos para ir mejorando y gestionando obras de infraestructura y el desarrollo integral de todo el territorio, teniendo en cuenta el ordenamiento territorial para un crecimiento planificado.

\section{Conclusiones}

A través de la historia la evolución de la dinámica poblacional de los distritos de Callahuanca y Otao ha sufrido una serie de cambios, sobre todo en lo concerniente a la migración, la población tuvo un desplazamiento de los pueblos situados a más de $3000 \mathrm{msnm}$, hacia los pueblos ubicados entre 1200 a $2500 \mathrm{msnm}$, como consecuencia de esta migración la población de las zonas alto andinas del distrito de Callahuanca se concentraron en el pueblo de Callahuanca y Barba Blanca. De otro lado, en el distrito de San Mateo de Otao, también la población se desplazó de los 3500 msnm hacia el fondo de la quebrada ubicándose en los pueblos de Canchacalla, Salpín, Cumbe y otros anexos de la quebrada. Esta migración ocasionó el despoblamiento de los pueblos que antiguamente eran las capitales de estos distritos, Chauca y el pueblito de San Mateo de Otao respectivamente.

En las entrevistas realizadas a los pobladores manifestaron que la migración es típicamente de los jóvenes quienes optan por buscar mejores destinos para estudiar y trabajar de preferencia en la capital y el extranjero.

Los cambios sociales que se han producido a lo largo de las últimas décadas: modificaciones en la estructura poblacional a partir, principalmente, de la migración por motivos laborales, los cambios de uso del terreno agrícola, así como la producción para exportación, hacen que el desarrollo en ambos distritos sea totalmente diferente: Callahuanca aprovecha la oportunidad para promover el desarrollo económico a partir de la comercialización de sus productos lo cual es viable a partir del uso de la carretera asfaltada que la une a Santa Eulalia; San Mateo de Otao está rezagado en este campo, por las limitaciones del uso de sus tierras y del permanente abandono de su espacio por la migración.

El estado, con su poca presencia, en cuanto a servicios de salud y educación, no es un agente presente y permanente en dichos distritos. Si bien es cierto que hay cobertura en este campo, pero con las limitaciones que se conocen en zonas del ámbito rural. De la misma manera, el Ministerio de Cultura y la Dirección Regional de Cultura del Gobierno Regional Lima Provincias tienen abandonadas las zonas arqueológicas en estos distritos, de tal manera que algunos de ellos están más deteriorados que hace algunos pocos años.

\section{Bibliografía}

Bermúdez, M. (2016). Desarrollo local del cantón de Coto Brus, sin desarrollo regional. ¿Realidad o utopía? En Planificación territorial, desarrollo sustentable y geo diversidad. Sevilla: Imprenta Caligraf.

Bravo, O. (2016). Desarrollo local como estrategia socio-política de cambio. En Planificación territorial, desarrollo sustentable y geo diversidad. Sevilla: Imprenta Caligraf.

CEPAL (2016). Desarrollo social inclusivo. Una nueva generación de políticas para superar la pobreza y reducir la desigualdad en América Latina y el Caribe. Santiago: Naciones Unidas Press.

Gobierno Regional Lima (2018). Análisis de situación de salud 2017 Región Lima. Lima: Dirección Regional de Salud - Gobierno Regional Lima.

Gobierno Regional Lima (2017). Análisis de situación de salud de la provincia de Huarochirí. Lima: Dirección Regional de Salud - Gobierno Regional Lima.

Minsa (2017). Perú: Indicadores nutricionales en niños, Sistema de información del estado nutricional. Periodo: enero-julio 2017. Lima: Instituto Nacional de Salud.

Pulgar Vidal, Javier (1996). Geografía del Perú. Lima: Ediciones PEISA.

VÁsquez, E. \& Medina, G. (2010). La comunidad campesina de San Mateo de Otao. En Investigaciones Sociales 24. Facultad de Ciencias Sociales de la UNMSM. Lima: UNMSM.

Banco Mundial (2017). Sitio Web: http://www.bancomundial.org/es/topic/socialdevelopment/overview (Visto: 12-04-2017).

Ministerio de Educación (2018). Sitio Web ESCALE - Estaddsticos de la Realidad Educativa: http://escale.minedu.gob.pe/web/inicio/padron-de-iiee (Visto: 14-11-2018). 